\title{
Solid-Phase Extraction of Aquatic Organic Matter: Loading- Dependent Chemical Fractionation and Self-Assembly
}

\author{
Xianyu Kong,* Thomas Jendrossek, Kai-Uwe Ludwichowski, Ute Marx, and Boris P. Koch*
}

Cite This: Environ. Sci. Technol. 2021, 55, 15495-15504

Read Online

ABSTRACT: Dissolved organic matter (DOM) is an important component in marine and freshwater environments and plays a fundamental role in global biogeochemical cycles. In the past, optical and molecular-level analytical techniques evolved and improved our mechanistic understanding about DOM fluxes. For most molecular chemical techniques, sample desalting and enrichment is a prerequisite. Solid-phase extraction has been widely applied for concentrating and desalting DOM. The major aim of this study was to constrain the influence of sorbent loading on the composition of DOM extracts. Here, we show that increased loading resulted in reduced extraction efficiencies of dissolved organic carbon (DOC), fluorescence and absorbance,

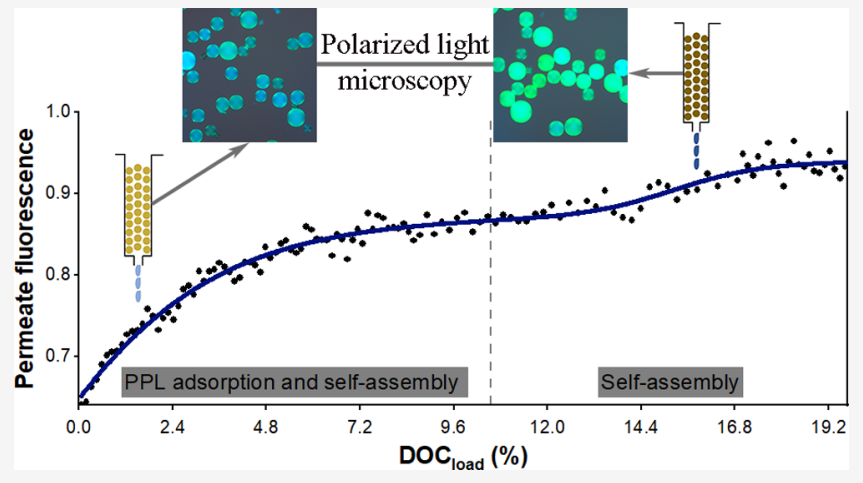
and polar organic substances. Loading-dependent optical and chemical fractionation induced by the altered adsorption characteristics of the sorbent surface (styrene divinylbenzene polymer) and increased multilayer adsorption (DOM self-assembly) can fundamentally affect biogeochemical interpretations, such as the source of organic matter. Online fluorescence monitoring of the permeate flow allowed to empirically model the extraction process and to assess the degree of variability introduced by changing the sorbent loading in the extraction procedure. Our study emphasizes that it is crucial for sample comparison to keep the relative DOC loading $\left(\mathrm{DOC}_{\text {load }}[\mathrm{wt} \%]\right)$ on the sorbent always similar to avoid chemical fractionation.

KEYWORDS: dissolved organic matter, fluorescence spectroscopy, EEMs, PARAFAC, RP-HPLC, scanning electron microscopy, polarized light microscopy, multilayer adsorption

\section{INTRODUCTION}

Dissolved organic matter (DOM) is a highly complex heterogeneous mixture of compounds comprising a large range of molecular size, polarity, or elemental composition, all of which vary considerably between freshwater and saltwater. $^{1-3}$ DOM plays an essential role as a large carbon reservoir in global biogeochemical carbon cycles, and an improved understanding of DOM biogeochemistry relies on molecular characterization. ${ }^{4-6}$ Water sample desalting and enrichment is a prerequisite for many analytical techniques, such as ultrahigh-resolution mass spectrometry (FT-ICRMS). ${ }^{7-9}$

Solid-phase extraction (SPE) is one of the most widely used techniques to concentrate and desalt DOM in marine and freshwater. ${ }^{10-12}$ Although other SPE sorbents also exhibited high recoveries, ${ }^{13,14}$ PPL (styrene divinylbenzene polymer) has become a popular extraction sorbent with the ability to retain moderately polar to nonpolar DOM at relatively high recoveries for dissolved organic carbon (DOC). ${ }^{10,15-17}$ However, PPL extractions are not quantitative and recover $\sim 20-90 \%$ of DOC in aquatic samples, resulting in molecular differences when comparing the DOM composition between original water and extracts. ${ }^{18-21}$ Unlike in one-compound systems, the efficiency of DOM extraction via SPE is not only driven by the interaction with the stationary phase but also affected by the concentrations, sizes, and polarities of molecules in DOM. Intermolecular effects and competitions affect the equilibria between the mobile and stationary phases. Many studies have compared the compositional or structural differences for original and extracted DOM, and some compared the influence of enrichment volume on the extraction efficiency. ${ }^{10,15,20-23}$ However, few studies have looked at the mechanistic details of potential fractionation and adsorption mechanisms that are caused by different loadings in SPE. ${ }^{22}$

Chromophoric DOM (CDOM), the optically active fraction of bulk DOM, also plays an important role in biogeochemical

Received: July 7, 2021

Revised: October 24, 2021

Accepted: October 25, 2021

Published: November 4, 2021

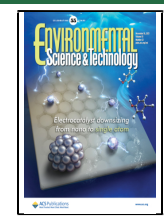


cycles. $^{24-26}$ Optical spectroscopy (absorbance and fluorescence) has been widely used to characterize the properties and dynamics of CDOM in the original matrix because of its relative ease of use and high sensitivity. ${ }^{27-29}$ Fluorescence excitation-emission matrices evaluated with parallel factor analysis (EEM-PARAFAC) is an effective tool for tracking and characterizing the source, distribution, composition, and turnover of fluorescent DOM (FDOM). ${ }^{30-33}$ Moreover, targeted analysis of specific DOM compounds (such as amino acids) or untargeted analysis (such as polarity assessment) using, for example, reversed-phase high-performance liquid chromatography (RP-HPLC) is also applied to chemically characterize DOM. ${ }^{18,34}$

The main objective of this study was to reveal the potential chemical fractionation mechanisms for PPL-extracted DOM induced by different loadings. For this, we established an online fluorometric monitoring of the permeate and applied microscopy to visualize the loading on the surface of PPL beads. We hypothesize that increased loading results in decreasing extraction efficiency and in optical and chemical fractionation. Based on the online monitoring data, we aimed at establishing an extraction model that helps to assess the analytical variability introduced by changing extraction mechanisms along increased sorbent loading.

\section{METHODS AND MATERIALS}

Sampling. Samples were collected at lower River Weser (Ws1, riverine sample) near the town of Minden, the outer River Weser estuary (Ws2, estuarine sample), the Southern North Sea (Ws3, Ms1, marine sample), and the fishery harbor near the Alfred Wegener Institute in Bremerhaven, Germany (Es1, Es2, estuarine sample). Es1 was used to carry out online fluorometric detection of the permeate DOM using PPL extraction. Es2 served to visualize the PPL sorbent surface using microscopy. Ms1 (high microbial degradation) was used to examine FDOM self-assembly on the PPL sorbent, and Ws1, Ws2, and Ws3 were used to explore loading- and sorbenttype-dependent changes in DOM extracts. All samples were filtered using precombusted glass fiber filters (GF/F, 1825-047, Whatman) and stored at $4{ }^{\circ} \mathrm{C}$ in the dark until analysis. All sampling materials were previously either precombusted at 450 ${ }^{\circ} \mathrm{C}$ or treated with $10 \%$ hydrochloric acid and well rinsed with ultrapure water. The relative DOC loading weight of the sorbent $\left(\mathrm{DOC}_{\text {load }}\right)$ was calculated as

$$
\begin{aligned}
\operatorname{DOC}_{\text {load }}(\text { wt \% })= & \operatorname{DOC}_{\text {conc }}\left(\mathrm{mg} \mathrm{L}^{-1}\right) \times \text { volume }_{\text {sample }}(\mathrm{L}) \\
& \div \text { mass }_{\text {sorbent }}(\mathrm{mg}) \times 100
\end{aligned}
$$

where $\mathrm{DOC}_{\text {conc }}$ is the DOC concentration of the original sample, volume sample $_{\text {is }}$ the volume of the extracted samples,

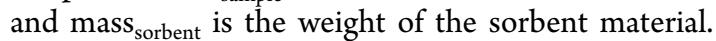

Experimental Setup. For online fluorometric detection (USB2000-FLG, $200 \mu \mathrm{m}$ slit, Ocean Optics spectrometer) of DOM in the permeate flow of a large-volume $(8.2 \mathrm{~L})$ estuarine sample (Es1) extraction, SPE cartridge (PPL; $200 \mathrm{mg}$; Bond Elut, Agilent Technologies) was conditioned with methanol (3 $\mathrm{mL}$ each, LiChrosolv, Merck) and acidified ultrapure water (3 $\mathrm{mL} ; \mathrm{pH}, 2 ; \mathrm{HCl}, 30 \%$ suprapure; Merck). The acidified water sample ( $\mathrm{pH}, 2 ; \mathrm{HCl}, 30 \%$ suprapure; Merck) was filled into reservoirs, which were connected by Luer adaptors to the SPE cartridge. The cartridge was fixed using an extraction support device (Visiprep, Supelco). The sample was drawn through the cartridge using Tygon tubings (SC0015, ISMATEC) and a peristaltic pump (ISM931C, ISMATEC) at a flow rate of 4.0 $\mathrm{mL} \min ^{-1}$. The permeate flow was passed through a flowthrough cell ( $V=750 \mu \mathrm{L}, 175050-\mathrm{QS}$, Hellma), and DOM was excited using light-emitting diodes (LLS LED, Ocean Optics) at $365 \mathrm{~nm}$ during the entire extraction. The emitted fluorescence signal was measured with a fiber-optic spectrometer (USB2000-FLG, $200 \mu \mathrm{m}$ slit, Ocean Optics spectrometer) and integrated over a wavelength range of 420-600 $\mathrm{nm}$. Processing and visualization of the data were performed using the instrument software (spectra suite, Ocean Optics, Supporting Information Table S1). Subsamples were collected from the permeate at the exit of the flow-through cell and measured for DOC concentration, EEMs, and absorbance (see below). Process blanks for each sorbent were performed by extracting acidified ultrapure water with the same procedure.

To further investigate the FDOM self-assembly on the PPL sorbent (200 mg; Bond Elut, Agilent Technologies), we collected the permeate for the volumes $0-200 \mathrm{~mL}(0-0.1 \mathrm{wt}$ $\left.\% \mathrm{DOC}_{\text {load }}\right)$ and $200-400 \mathrm{~mL}\left(0.1-0.2 \mathrm{wt} \% \mathrm{DOC}_{\text {load }}\right)$ for the Ms1 SPE process. PPL extractions were performed in triplicate, and the EEMs of the permeate were averaged for each treatment, and the EEM extraction efficiency was calculated by subtracting the permeate EEMs from the EEMs of the original sample.

In addition, four discrete enrichment volumes (100, 250, 500 , and $1000 \mathrm{~mL}$ ) of samples Ws1-Ws3 were extracted using PPL and C8 cartridges (200 mg; Bond Elut, Agilent Technologies). All cartridges were eluted with $1.5 \mathrm{~mL}$ of methanol and stored at $-18{ }^{\circ} \mathrm{C}$ until analysis to prevent esterification. $^{35}$

Microscopy. To visualize DOM adsorption on the surface of the PPL sorbent, three treatments of PPL sorbents were used for scanning electron microscopy (SEM) and polarized light microscopy. PPL cartridges were conditioned and (i) not loaded at all, (ii) loaded with $0.5 \mathrm{~L}$ estuarine water, or (iii) loaded with $5 \mathrm{~L}$ estuarine water (Es2). All PPL sorbents were dried with $\mathrm{N}_{2}$ prior to the microscope visualizations. The PPL particles were mounted on stubs, sputter-coated (Emscope SC500; Ashford, UK) with gold-palladium, and viewed at 10 $\mathrm{kV}$ under a scanning electron microscope (FEI Quanta FEG200; Eindhoven, the Netherlands). For polarized light microscopy, a mercury vapor lamp was used as the light source (Axioskop50, Axiocam, Axiovision software; Carl Zeiss, Germany).

DOC Measurement. DOC and total dissolved nitrogen were determined by high-temperature catalytic oxidation, nondispersive infrared spectroscopy, and chemiluminescence detection (TOC-VCPN, Shimadzu). For the determination of the sample DOC content in the methanol extracts, a $50 \mu \mathrm{L}$ aliquot of each methanol extract was evaporated under $\mathrm{N}_{2}$ and subsequently redissolved in $6.5 \mathrm{~mL}$ of ultrapure water. ${ }^{3}$ The DOC extraction efficiency was calculated for all samples as DOC concentration in the extract divided by DOC concentration in the corresponding original sample and considering the enrichment factor. The DOC extraction efficiency for Es1 was additionally acquired by subtracting the permeate DOC from the original DOC.

Optical Spectroscopy Measurement. EEMs and absorbance were measured for permeate samples collected at discrete time intervals during SPE using a fluorometer (Horiba Aqualog) equipped with a CCD detector. Excitation and absorbance wavelengths ranged from 240 to $600 \mathrm{~nm}$ in $3 \mathrm{~nm}$ 


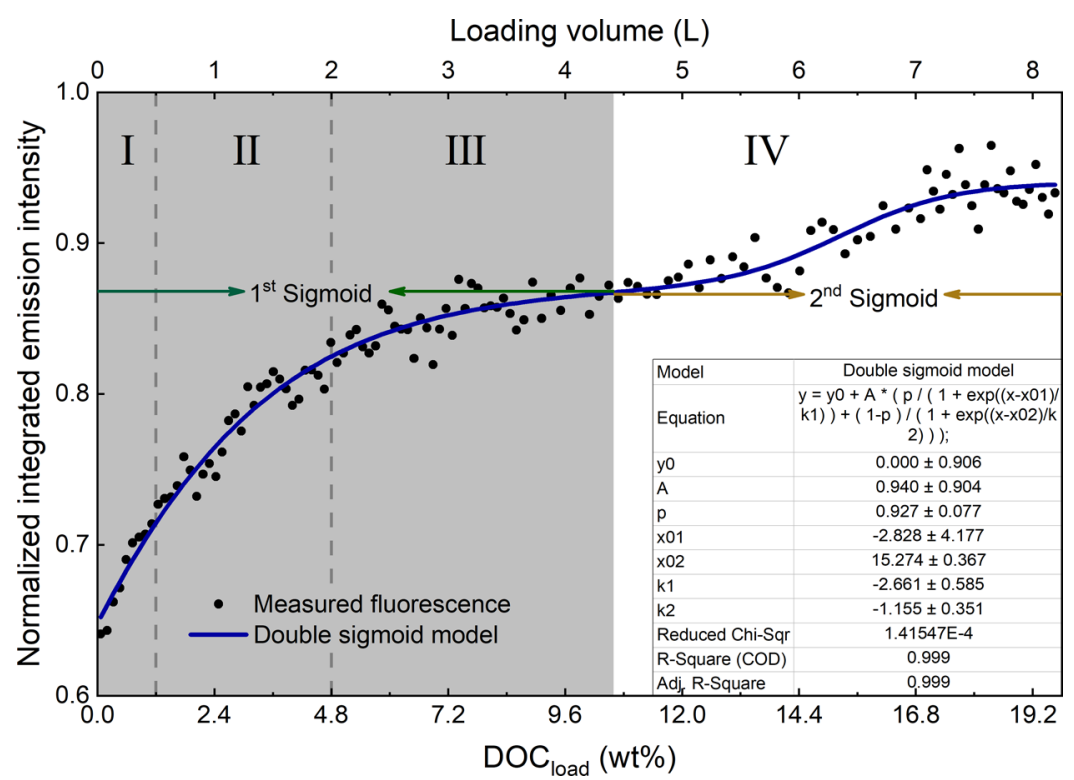

Figure 1. Online fluorometric detection (dots; Ex: 365 nm; Em: 420-600 nm) of SPE (PPL, $200 \mathrm{mg}$ ) of a large-volume estuarine water sample (Es1): a double-sigmoid model (blue line) was fitted to the normalized integrated emission intensity in the permeate as a function of $\mathrm{DOC}_{\text {load }}$ (DOC mass loading vs PPL mass in wt \%). Normalized permeate integrated emission intensity was calculated by dividing the integrated emission intensity of the permeate by the original sample. The first sigmoid transitioned to the second sigmoid process at the local minimum of DOC $\mathrm{Coad}$ of $10.6 \mathrm{wt} \%$ (equiv. to $4.4 \mathrm{~L}$ loading volume). Gray and white areas denote first and second sigmoid processes, respectively. Dashed vertical lines denote different loading stages, as derived from the cluster analysis (cf. Figure $2 b$ ).
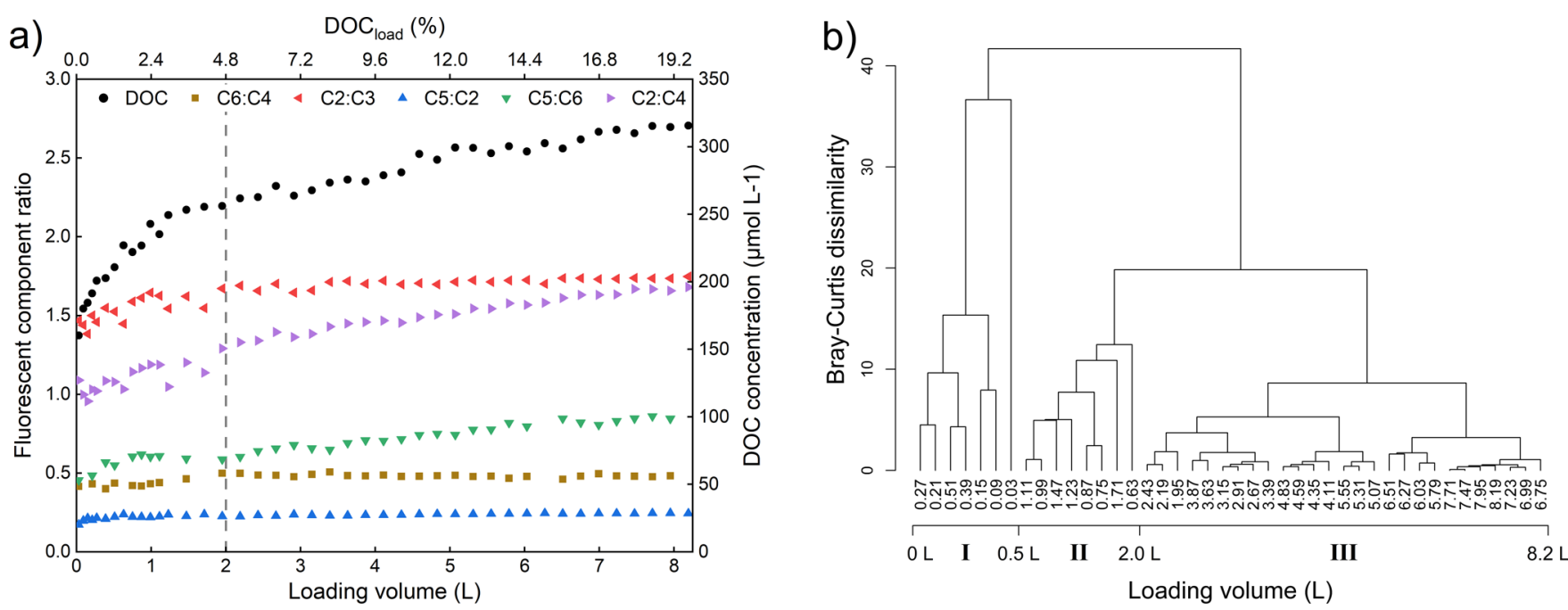

Figure 2. Loading-related changes in permeate DOC concentration and fluorescence: (a) DOC concentration and fluorescence component ratios derived from PARAFAC analysis and (b) cluster analysis of different enrichment volumes based on six fluorescent components in the permeate during SPE (PPL, $200 \mathrm{mg}$ ) of a large-volume (loading) estuarine DOM sample (Es1).

increments and emission wavelengths from 220 to $620 \mathrm{~nm}$ (increment $\sim 3.3 \mathrm{~nm}$ ). EEMs and absorbance data were processed by staRdom package in $\mathrm{R}$ studio (version 3.5.1). ${ }^{36}$ The fluorescence spectra were measured by ultrapure water blank correction, inner filter effect correction, and Raman normalization (dividing by the Raman peak of pure water at an integrated excitation of $350 \mathrm{~nm}$ with an emission wavelength interval of $371-428 \mathrm{~nm}) .{ }^{37}$ Based on the acquired data, a PARAFAC analysis was carried out. ${ }^{38}$ The fluorescence index (FI) was calculated, based on the ratio of the emission intensity at a wavelength of $450 \mathrm{~nm}$ and that at $500 \mathrm{~nm}$, obtained for a fixed excitation wavelength of $370 \mathrm{~nm},{ }^{39}$ and the biological index (BIX) was calculated by the ratio of the emission intensity at $380 \mathrm{~nm}$ divided by that at $430 \mathrm{~nm}$ with a fixed excitation wavelength of $310 \mathrm{~nm} .^{40}$ Spectral slopes $\left(S_{275-295}\right.$ and $\left.S_{350-400}\right)$ were calculated using nonlinear leastsquares fit, and the spectral slope ratio $\left(S_{\mathrm{R}}\right)$ was calculated by the ratio of $S_{275-295}$ and $S_{350-400 \cdot}{ }^{41}$ The fluorescence extraction efficiency was calculated using the extracted fluorescence signal divided by the fluorescence signal of the corresponding original sample.

Polarity Profile Measurement. The polarity profile of methanol extracts was analyzed using an HPLC method. ${ }^{18}$ Chromatographic separation was performed on an RP-HPLC system (Hitachi) equipped with an autosampler (L-2200), pump (L-2130), column oven (L-2300), fluorescence detector (L-2485), and diode array detector (L-2450). In each analysis, $5 \mu \mathrm{L}$ of methanol extracts was injected and separated according 
to polarity using a $\mathrm{C} 18$ reversed-phase column (PLRP-S column $3 \mathrm{u} 300 \AA$, $150 \times 2.1 \mathrm{~mm}$, Agilent Technologies). The mobile solvents, ultrapure water and methanol, are used in a gradient program (Supporting Information Table S2). The separated substances were characterized optically by a fluorescence detector, with excitation at $260 \mathrm{~nm}$ and emission at $430 \mathrm{~nm}$. The amount of the separated organic substances was estimated from absorbance at a wavelength of $210 \mathrm{~nm}$ using a diode array detector. This wavelength was chosen because it is sensitive to most functional groups that dominate in DOM. ${ }^{42}$

Amino Acid Measurement. Amino acid analysis in methanol extracts was based on a previous method. ${ }^{34}$ Amino acid derivatization and separation were performed on an RPHPLC system (Agilent Technologies) equipped with an autosampler (1200 Series G1329A), pump (1200 Series G1312A), column oven (1260 Infinity G1316A), fluorescence detector (1200 Series G1321A), and diode array detector (1260 Infinity G1315D). Details for amino acid measurement are described in the Supporting Information (S1).

Statistical Analyses. Cluster analysis based on the groupaverage method was performed by the "pvclust" package in $\mathrm{R}$ studio (version 3.5.1). The Bray-Curtis dissimilarity measures based on relative abundances were used to visualize sample similarities. For FDOM changes in the permeate of Es1 extraction, six PARAFAC components were used. For amino acid data, the proportion of individual amino acids in the extracts was used. The double sigmoid model was calculated using the software Origin (2018).

\section{RESULTS}

Online and Offline Analyses of the Permeate. Online monitoring of FDOM in the permeate allowed tracking of the quantitative and qualitative changes related to increased DOC loading (Figure 1 and 2). Inherently, this also yields information on the optical changes of the extracted DOM, as these can be deduced from the difference between FDOM in the original water and the permeate. Despite the suggestion from the previous study that varying flow rate had little influence on DOC extraction efficiency and composition, ${ }^{22}$ we used a pump to keep the flow rate constant and hence eliminated flow rate as a factor in the extraction model. A double-sigmoid model gives an excellent representation (coefficient of determination was 0.999 and reduced Chisquared value was near to 0; cf. Supporting Information S2) of changes in the permeate fluorescence integrals $(y)$ with increased SPE column loading (Figure 1)

$$
y=y_{0}+A\left[\frac{p}{1+\mathrm{e}^{x-x_{01} / k 1}}+\frac{1-p}{1+\mathrm{e}^{x-x_{02} / k 2}}\right]
$$

where $y_{0}$ and $A$ are the left and right asymptotes of $y$, and $A$ is the maximum value of $y$ corresponding to the limit $x \rightarrow \infty$ and constrained to $\leq 1$ in this case; $p$ is the fraction of the first phase and $1-p$ is the fraction of the second phase; $x_{01}$ and $x_{02}$ are the centers of the two phases; and $k 1$ and $k 2$ are the slope factors that determine the rise of the first and second phases. ${ }^{43}$

The double-sigmoid approach highlights the transition of adsorption characteristics after $10.6 \mathrm{wt} \% \mathrm{DOC}_{\text {load }}$, where the second sigmoid process starts to deviate from the first sigmoid.

Applying PARAFAC analysis to EEMs of discrete permeate samples resulted in six underlying components (Supporting Information Figure S1). Based on the fluorescence maxima, components $\mathrm{C} 2, \mathrm{C} 3$, and $\mathrm{C} 5$ can be attributed to terrestrial humic-like sources, ${ }^{44-49}$ while C4 was previously interpreted as representing marine and microbial humic-like fluorophores (peak M). ${ }^{24,50} \mathrm{C} 1$ represents terrestrial and marine humic-like sources, $^{44,48,51}$ and C6 was categorized as a protein-like component (tryptophan-like peak $\mathrm{T}$ ) with biological autochthonous origin. ${ }^{30,50,52}$ The average extraction efficiency for all components varied from $88.0 \%$ at the beginning to $24.6 \%$ at the end. A cluster analysis based on six components revealed most pronounced changes of the permeate fluorescence after the first 0.5 and $2 \mathrm{~L}$ of extraction. Guided by multivariate statistics and the double-sigmoid model, we split our data into four different intervals of $\mathrm{DOC}_{\text {load }}$ (Figure 1): 0-1.2 wt \% (I), $1.2-4.8$ wt \% (II), 4.8-10.6 wt \% (III), and 10.6-19.7 wt \% (IV).

For permeate flow, we observed a continuous increase in DOC concentration, PARAFAC component intensity, and absorbance at $254 \mathrm{~nm}$ (a254) with an increased column loading (Figures 2a and Supporting Information S2a,b). At the beginning of extraction ( DOC $_{\text {load }}$ : $0-1.2 \mathrm{wt} \%$ ), virtually all fluorescent compounds were retained and DOC concentration, absorbing and fluorescing compounds were very low in the permeate and continuously increased with DOC loading. As the absolute changes in these parameters could be simply related to a yield change, we evaluated the ratio changes in the permeate that undoubtedly highlight compositional changes: for example, the ratios of terrestrial components $(\mathrm{C} 2: \mathrm{C} 3$ and $\mathrm{C} 5: \mathrm{C} 2)$ and microbial components (C6:C4) increased strongly during the first $4.8 \mathrm{wt} \%$ of $\mathrm{DOC}_{\text {load }}$ and only increased slightly thereafter (Figure 2a). However, the ratios between terrestrial and microbial components (i.e., C5:C6 and C2:C4) still showed a continuous increase thereafter. Hence, FDOM components derived from different sources had different sorbent affinities, and FDOM composition with similar sources showed little chemical fractionation after $4.8 \mathrm{wt}$ $\%$ of $\mathrm{DOC}_{\text {load }}$.

Furthermore, spectral slopes and optical indices were calculated to investigate the changes in chemical composition. During the first $2 \mathrm{~L}$ of enrichment, the permeate showed a pronounced decrease in $S_{275-295}, S_{R}$, and FI, while $S_{350-400}$ and BIX increased (Supporting Information Figure S2c,d). After 2 L extraction, spectral slopes and spectral slope ratio showed only little variation, whereas BIX and FI decreased continuously in the permeate.

Motivated by the results from the large-volume experiment (Figure 2) and to better understand FDOM self-assembly, we extracted and analyzed a marine sample (Ms1) that was subject to higher microbial degradation due to $\sim 3$ months storage at room temperature and showed higher ultraviolet A (UVA) fluorescence $\left(\mathrm{Ex}_{\max }<300 \mathrm{~nm}, \mathrm{Em}_{\max }<400 \mathrm{~nm}\right.$ ) (Supporting Information Figure S3a). Compared to the first $200 \mathrm{~mL}$ of the collected permeate, we observed that the permeate collected between 200 and $400 \mathrm{~mL}$ sample extraction (0.1-0.2 wt \% $\left.\mathrm{DOC}_{\text {load }}\right)$ showed a lower extraction efficiency in the high excitation wavelength region (peak at Ex/Em: $335 / 380 \mathrm{~nm}$ ), while it is higher in the UVA region (peak at Ex/Em: 275/330 $\mathrm{nm}$; Supporting Information Figure S3b).

Loading- and Sorbent-Type-Dependent Changes in DOM Extracts. To further evaluate how loading affected the composition and chemical properties of the solid-phase extracted DOM, four discrete water volumes $(100,250,500$, and $1000 \mathrm{~mL}$ ) from three aquatic locations (riverine Ws1, estuarine Ws2, and marine Ws3) were extracted using PPL and 
Table 1. Comparison of DOM Extracts Based on Sorbent Type and Sample Origin ${ }^{a}$

\begin{tabular}{|c|c|c|c|c|c|c|}
\hline \multirow[b]{2}{*}{ source } & \multirow[b]{2}{*}{ extraction volume $(\mathrm{mL})$} & \multirow[b]{2}{*}{$\mathrm{DOC}_{\text {load }}($ wt \%) } & \multicolumn{2}{|l|}{ PPL } & \multicolumn{2}{|l|}{$\mathrm{C} 8$} \\
\hline & & & DOC extraction efficiency (\%) & polarity ratio & DOC extraction efficiency (\%) & polarity ratio \\
\hline \multirow[t]{4}{*}{ Ws1 riverine } & 100 & 0.16 & 57.3 & 1.1 & 35.9 & 0.7 \\
\hline & 250 & 0.40 & 48.5 & 1.0 & 27.5 & 0.6 \\
\hline & 500 & 0.80 & 45.0 & 0.9 & 26.5 & 0.5 \\
\hline & 1000 & 1.60 & 42.5 & 0.5 & 24.4 & 0.5 \\
\hline \multirow[t]{4}{*}{ Ws2 estuarine } & 100 & 0.18 & 61.2 & 3.4 & 39.8 & 2.7 \\
\hline & 250 & 0.45 & 60.9 & 2.5 & 37.2 & 2.3 \\
\hline & 500 & 0.91 & 59.8 & 2.1 & 34.1 & 1.7 \\
\hline & 1000 & 1.81 & 55.8 & 1.2 & 30.2 & 1.2 \\
\hline \multirow[t]{4}{*}{ Ws3 marine } & 100 & 0.09 & 65.7 & 3.1 & 45.0 & 1.5 \\
\hline & 250 & 0.22 & 58.9 & 2.2 & 32.9 & 1.6 \\
\hline & 500 & 0.44 & 55.2 & 1.9 & 29.7 & 1.0 \\
\hline & 1000 & 0.89 & 51.7 & 1.7 & 27.3 & 1.1 \\
\hline
\end{tabular}

${ }^{a}$ Note: stationary phase was $200 \mathrm{mg}$ for both cartridges; DOC concentrations for Ws1, Ws 2 , and Ws3 were 267,302 , and $148 \mu \mathrm{mol} \mathrm{L}^{-1}$, respectively. Previous studies with larger sample numbers reported a standard deviation for DOC extraction efficiency of about $2-7 \%$. 10,53

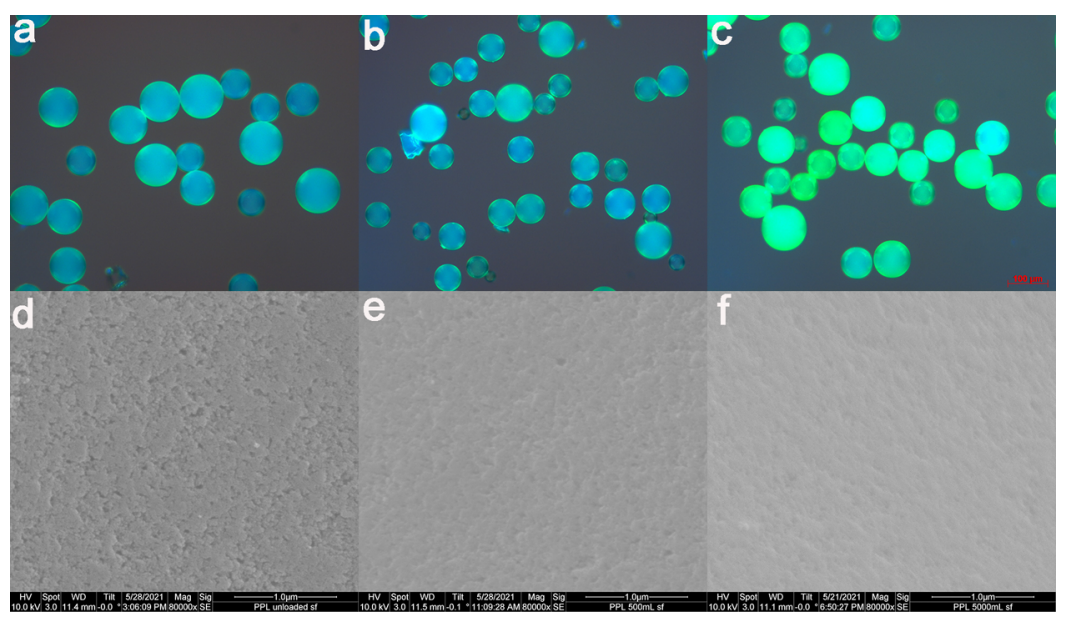

Figure 3. Images of polarized light microscopy at $10 \times$ magnification $(a-c)$ and SEM at $80,000 \times$ magnification (d-f) for the surface of unloaded PPL (a,d), PPL loaded with $0.5 \mathrm{~L}(\mathrm{~b}, \mathrm{e})$, and PPL loaded with $5 \mathrm{~L}(\mathrm{c}, \mathrm{f})$ of the estuarine sample Es2.

C8 cartridges. PPL sorbents showed a much larger extraction efficiency than C8 sorbents (Table 1). For both sorbent materials, comparing $100 \mathrm{~mL}\left(\mathrm{DOC}_{\text {load }}=0.09-0.18 \mathrm{wt} \%\right)$ with the $1000 \mathrm{~mL}$ sample volume $\left(\mathrm{DOC}_{\text {load }}=0.89-1.81 \mathrm{wt}\right.$ $\%)$, DOC extraction efficiency decreased by $11.5-17.7 \%$ for the riverine and marine samples and only by $5.4-9.6 \%$ for the estuarine sample.

The polarity profile of methanol extracts for Ws1, Ws2, and Ws3 was determined by RP-HPLC. According to the gradient program (Supporting Information Table S2), the first fraction was defined as polar water-soluble substances (retention time $<16 \mathrm{~min}$ ), whereas a fraction of less polar compounds eluted in the methanol-soluble fraction (retention time $>16 \mathrm{~min}$ ). Polarity ratio was calculated by the area of polar fraction versus less polar fraction to illustrate the polarity changes (Table 1). It was noteworthy that polarity ratio decreased with increasing sample volumes $\left(\mathrm{DOC}_{\text {load }}\right)$. Comparing $100 \mathrm{~mL}$ with the $1000 \mathrm{~mL}$ extraction volume, the average decrease of polarity ratio was approximately 18 and $12 \%$ for all samples extracted with PPL and C8, respectively. As expected, the PPL sorbent extracted more polar compounds than the C8 sorbent (Ws1: 1-14\%, Ws2: 0-4\%, Ws3: 7-15\%).

To explore the loading-related qualitative changes of the amino acid composition in solid-phase extracts, we evaluated the proportional changes of individual amino acids: compared to the changes in the fluorescence characteristics of the permeate, individual amino acid proportions only varied by $1-$ $3 \%$ between different volumes, independent of the sample origin and sorbent type used (Supporting Information Table S4). Although these results were also generally supported by a cluster analysis (Supporting Information Figure S4), the statistical method revealed that the amino acid composition in $100 \mathrm{~mL}$ extractions differed most strongly from $1000 \mathrm{~mL}$, emphasizing that also amino acid composition varies with extraction volume.

Imaging of Loading-Related Changes of the Sorbent Surface. Microscopic visualizations of the PPL surface were performed using $200 \mathrm{mg}$ cartridges that were either unloaded

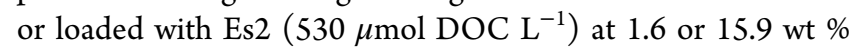
DOC $_{\text {load }}$ (equivalent to 0.5 and $5 \mathrm{~L}$ loading volumes, respectively). Images of the PPL surface from polarized light microscopy and SEM were compared between 0.5 and $5 \mathrm{~L}$ loadings. The continuous change of surface color (Figure $3 \mathrm{a}-$ c), the decrease of texture (Figure $3 \mathrm{~d}-\mathrm{f}$ ), and the visible DOM surface layer (Supporting Information Figure S5d) illustrate how the porous surface of PPL was increasingly covered from the unloaded state to 0.5 and $5 \mathrm{~L}$ loadings. 


\section{DISCUSSION}

Inverse Online Monitoring of the Extraction Procedure and Empirical Modeling. In our study, we used an inverse online monitoring approach to track chemical changes during aquatic DOM SPE extraction. We hope that this simple procedure can be easily applied for other sorbents and environmental samples so that methodological biases introduced by SPE in aquatic research can be more conveniently assessed in future. It should be noted that classical adsorption models such as Thomas model, ${ }^{54}$ Langmuir isotherm, ${ }^{55}$ or Dubinin-Astakhov isotherm ${ }^{56}$ are difficult to be applied due to the heterogeneous and complex nature of aquatic DOM. Although we do not know precisely how many organic compounds are contained in water, mass spectrometry yields at least 10,000 different molecular masses and an unknown dimension of structural isomers within each sample. For this reason, we chose an exclusively empirical modeling approach of the permeate fluorescence. Starting with a sigmoid Boltzmann model for the breakthrough curve of singlecompound $\mathrm{SPE}^{57,58}$ that was similar to, for example, nonlinear Langmuir isotherm, our online monitoring experimental data highlighted a considerable deviation, which led to a doublesigmoid model that better reconstructed the measured data. Based on the assumption that DOM extraction equilibria are controlled by unequal contributions of PPL physisorption and multilayer adsorption (DOM self-assembly), we modeled the permeate fluorescence by the double-sigmoid equation (Figure 1). Given the choice of sample and sorbent type in our experiment, the second sigmoid process deviated from the first sigmoid process at $\mathrm{DOC}_{\text {load }}>10.6 \mathrm{wt} \%$ (equivalent to $4.4 \mathrm{~L}$ loading volume of Es1).

Self-Assembly-An Important Mechanism during DOM SPE. Despite a very large ratio of the sample volume $(8.2 \mathrm{~L})$ versus mass of the sorbent $(200 \mathrm{mg}$ PPL) in our online monitoring experiment, we did not observe a capacity limit of stationary phase that would have been indicated by a constant fluorescence signal toward the end of SPE. Although we found a notable decrease in DOC extraction efficiency from lower to higher extraction volumes, we still observed considerable DOC extraction $(21.2 \%)$ at a sample volume of $>8 \mathrm{~L}$. According to the manufacturer, PPL can extract up to $12 \mathrm{wt} \%$ of the sorbent mass (pers. comm., Agilent Technologies). In order to facilitate comparisons between extractions of varying sorbent amounts, sample volume, and concentrations, the relative DOC loading weight on the column $\left(\mathrm{DOC}_{\text {load }}\right)$ is a very helpful parameter: in our experiment, for $200 \mathrm{mg}$ PPL and a sample volume of $8.2 \mathrm{~L}$ having a DOC concentration of 400.7 $\mu$ mol L L ${ }^{-1}, \mathrm{DOC}_{\text {load }}$ was $19.7 \mathrm{wt} \%$. Assuming that DOC contributes half of the total DOM mass and given an overall DOC extraction efficiency of $\sim 31.0 \%$ for Es1 (calculated by the integral of permeate DOC concentration in Figure 2a), the maximum capacity of the stationary phase was exceeded in our experiment. The discontinuous changes in the DOC extraction efficiency as well as absorbing and fluorescing compounds suggested a change in the predominant extraction mechanism with increased loading. Additional extractions using four discrete smaller volumes (Table 1) confirmed the online monitoring results and a previous study that reported decreasing DOC recovery with increasing sample volume. ${ }^{22}$

The discontinuous changes we observed could not be explained by just an increased coverage of the stationary PPL phase. Despite reaching the capacity of the sorbent toward the end of our extraction, DOC extraction efficiency was still relatively high (Figure 2a). We therefore hypothesized that with the increasing loading of PPL surface the predominant extraction mechanism shifts from DOM-PPL physisorption to an increased multilayer adsorption of the DOM adsorbate. In aquatic science, a mechanism similar to multilayer adsorption is known as DOM "self-assembly". This important process contributes to particle formation in aquatic environment: DOM polymers assemble into microgels by noncovalent bonds such as electrostatic, hydrogen, hydrophobic, or van der Waals bonds. ${ }^{59-61}$ In the following, we, therefore, use the term "selfassembly" as a synonym for multilayer adsorption.

Polarized light microscopy and SEM revealed a gradual change of surface texture and color, clearly showing the increasing and homogeneous loading of DOM on the PPL surface (Figure 3). Based on the assumption that the density of DOM and PPL is comparable and that the weight of DOM is approximately double of the DOC weight, it can be roughly estimated that the radius of PPL particles increased by $5 \%$ given a $31.8 \mathrm{mg}$ DOC loading (equivalent to $5 \mathrm{~L}$ loading of Es2) on $200 \mathrm{mg}$ of PPL. This massive surface coverage, combined with the observation that DOC is still extracted at larger loadings, supports our assumption that self-assembly is responsible for the ongoing DOC extraction beyond the capacity of the sorbent. Given that DOM adsorption and selfassembly will be competing processes, self-assembly likely also contributes to chemical fractionation at smaller loadings. However, looking at the differences of the gradients in the first and second sigmoid phases (Figure 1), we assume that the average enthalpy yielded by DOM adsorption on PPL is considerably higher than the enthalpy of DOM self-assembly. Therefore, both processes unequally contribute to the overall DOC extraction efficiency and chemical fractionation along the extraction process.

Chemical Fractionation of Complex Organic Matter during SPE. Most importantly for molecular DOM studies, our results show a loading-dependent qualitative chemical change in the permeate that can be considered as inverse changes of the extracted organic matter. It should be noted though that we expect our online permeate monitoring to be more sensitive to compositional changes compared to the changes analyzed in the extracts. The reason for this is that the extracts represent cumulated changes over a larger loading, which might contribute to the low variability observed in our amino acid composition experiment (Supporting Information Figure S4 and Table S4). In consistence with previous studies, ${ }^{10}$ a preferential extraction of terrestrial DOC was observed by slightly higher efficiencies for estuarine samples compared to marine samples (Table 1). Different from previous studies, we found unexpectedly low DOC extraction efficiencies for riverine samples, for which we only can speculate that salt discharges or locally different organic matter sources at the respective sections of River Weser are possible explanations.

Although fluorescence analysis of DOM typically does not require an extraction step, it is a helpful technique to document loading-related chemical changes. In particular, the change of ratios of fluorescent components during the first $2 \mathrm{~L}$ of SPE $\left(\mathrm{DOC}_{\text {load }} \leq 4.8 \mathrm{wt} \%\right.$, Figure $\left.2 \mathrm{a}\right)$ highlights substantial chemical fractionation. At the beginning of extraction $(0-0.5$ $\mathrm{L}, \mathrm{DOC}_{\text {load }}: 0-1.2 \mathrm{wt} \%$ ), fluorescent substances were almost quantitatively retained on the unloaded PPL. Between 0.5 and $2 \mathrm{~L}$ sample volume ( $\left.\mathrm{DOC}_{\text {load }}: 1.2-4.8 \mathrm{wt} \%\right)$, the increasing 
fluorescence signal in the permeate reflected fewer available polymer binding sites, and after $2 \mathrm{~L}$ of extraction, DOM selfassembly dominated. Such loading-dependent fractionations can also affect interpretations on aquatic organic matter composition, for example, with respect to the contribution of organic matter sources: the estuarine water used for the online extraction experiment (salinity of 11.6) contained a mixture of terrestrial and marine-derived organic matter that is partially reworked by microbial activity. We observed a stronger decrease in the extraction efficiency of microbial and proteinlike components (i.e., C4 and C6) within the first $2 \mathrm{~L}$ extraction $\left(\mathrm{DOC}_{\mathrm{load}}\right.$ of $\left.\leq 4.8 \mathrm{wt} \%\right)$, whereas the extraction efficiency for terrestrial humic-like components (i.e., C2, C3, and C5) declined more at higher loadings where self-assembly predominated (Supporting Information Figure S2a). FI ${ }^{39}$ is commonly used as an indicator to distinguish the DOM source: low FI values suggest that water samples are dominated by terrestrially derived substances, whereas high values are indicative of microbially derived DOM. ${ }^{32,62}$ FI value of 1.3 for the original estuarine water Es1 showed that bulk DOM was mainly derived from terrestrial sources. In the permeate of our online experiment, FI decreased continuously, indicating a higher loss of terrestrially derived organic matter with increasing loading. In addition, the index of recent autochthonous (microbial-derived) contribution (BIX) ${ }^{40}$ showed a loading-dependent increase of microbial-derived DOM in the permeate before $2 \mathrm{~L}$ of the enrichment and a loss at higher volumes (Supporting Information Figure S2c). These observations are in agreement with our interpretation that terrestrial DOM has a high affinity to PPL, whereas microbial humic-like and protein-like components were preferentially extracted by self-assembly. Amino acid analysis with four discrete enrichment volumes showed that the relative amino acid composition in methanol extracts changes slightly with different enrichment volumes (Supporting Information Figure S4 and Table S4), an observation supporting the fact that peptides or proteins showed higher self-assembly capabilities. $59,61,63,64$

The slope ratio $S_{R}$ was previously shown to be negatively correlated with molecular weight and DOM aromaticity ${ }^{29,41,65}$ and therefore also a good indicator for changes in chemical composition along the extraction. During the first $2 \mathrm{~L}$ of extraction, $S_{\mathrm{R}}$ decreasing in the permeate indicated the increasing loss of the aromatic content. At higher volumes, we only observed little changes for $S_{\mathrm{R}}$ and assume that $\pi-\pi$ interactions between PPL and aromatic DOM decreased as a consequence of increased loading of the polystyrene surface. It has been previously shown that marine DOM is characterized by a larger contribution of aliphatic structural features in comparison to the terrestrially derived DOM, which is characterized by a higher aromaticity and more hydroxyl and carboxyl functionalities. ${ }^{23,66,67}$ An earlier study ${ }^{20}$ revealed higher PPL recoveries for fluorescing terrestrial DOM compared to marine DOM and lower recoveries for biopolymers (i.e., proteins, polysaccharides, and amino sugars).

Increased loading also resulted in a decreased average polarity of organic substances in the extracts. It has been reported that PPL preferentially extracts more hydrophobic DOM and has a low capacity for highly polar substances. ${ }^{5,10,22}$ A previous study that performed a large-scale extraction (12.5 L) showed a compositional shift along increasing methanol elution volumes, from relatively polar and marine-derived to relatively nonpolar and terrestrial-derived DOM. ${ }^{5}$ Given the results of our study, these results might also be related to an increasing contribution of DOM self-assembly. Previous studies demonstrated that biopolymers including proteins, polysaccharides, and nucleic acids are more likely to assemble into microgels. ${ }^{59-61} \mathrm{DOM}$ self-assembly is therefore highly dependent on DOM origin and composition and is favored in samples that were subject to microbial degradation. ${ }^{60,68,69}$ Microbial degradation promotes the production of carboxylrich alicyclic molecules (CRAM) by consuming the bioavailable DOM in the euphotic layer. ${ }^{70}$ CRAM is an important chemical feature in PPL-extracted $\mathrm{DOM}^{20,66,71}$ that also can facilitate aggregation and microgel formation. ${ }^{72}$ This general observation is in agreement with our findings that selfassembly increases the relative recovery of protein-like and microbial humic-like DOM. It is also consistent with the results of our experiment that compared the optical features of permeates at different $\mathrm{DOC}_{\text {load }}$ (Supporting Information Figure S3), which suggested particularly strong self-assembly for UVA fluorescent compounds.

Implications for SPE of Aquatic Natural Organic Matter. Our findings have important implications for the procedure and interpretation of SPE of aquatic organic matter. All of the bulk and optical/chemical changes we observed were dependent on $\mathrm{DOC}_{\text {load }}$. Different from the SPE of single compounds, increased loading of the sorbent affected the adsorption equilibria for each compound contained in the complex organic matter. If similar volumes of samples with vastly different organic carbon concentration are extracted, analyzed, and compared for molecular features, ${ }^{73}$ it is therefore critical to minimize the variances introduced by different loadings. Ideally, this could be achieved by harmonizing $\mathrm{DOC}_{\text {load }}$ by analyzing the sample DOC concentration first and adjusting the sample extraction volume accordingly, so that similar sorbent loading is reached for all samples in the sample set. ${ }^{74}$ Alternatively, absorption or fluorescence measurements of the original sample before extraction might serve as a rough proxy for organic carbon concentration. If the sample processing is performed in field studies, this might be a feasible alternative to determine suitable loading volumes, compared to the elaborate determination of organic carbon concentration. It is important to note that, for reasons of feasibility, we defined $\mathrm{DOC}_{\text {load }}$ by the DOC concentration, sample volume, and sorbent mass. DOM samples derived from different sources will have different affinities to the sorbent and self-assembly, both affecting the overall extraction efficiency and, therefore, the effective loading of the stationary phase.

Online optical monitoring of the permeate flow was a simple and effective tool to track the performance and qualitative chemical changes in the permeate. The resulting data allowed modeling the extraction process, which in turn allowed to assess the variability introduced by different sorbent loadings. Within our estuarine sample extraction, an increase of $\mathrm{DOC}_{\text {load }}$ from $x_{1}$ wt $\%$ to $x_{2}$ wt $\%$ resulted in a calculated increase of total fluorescence in the permeate of

$$
\begin{gathered}
94.0\left[\frac{0.927}{1+\mathrm{e}^{x_{2}+2.828 /(-2.661)}}+\frac{0.073}{1+\mathrm{e}^{x_{2}-15.274 /(-1.155)}}\right. \\
\left.-\frac{0.927}{1+\mathrm{e}^{x_{1}+2.828 /(-2.661)}}-\frac{0.073}{1+\mathrm{e}^{x_{1}-15.274 /(-1.155)}}\right] \%
\end{gathered}
$$

If the total fluorescence would be used to compare samples in a sample set, the model can help to compare the variability 
introduced by differences in loading versus the variability between samples in the sample set.

Our results also underpin the fact that different loadings affect the quantification of single compounds that are solidphase-extracted from water samples with complex organic matrices, such as natural aquatic environments, effluents, or aquaculture systems. The quantification of specific analytes such as organic pollutants, metabolites, or ligands is affected by the overall sorbent loading because the complex organic matrix alters the surface of the sorbent and, therefore, changes the adsorption equilibrium of the analyte. At a very high DOC loading, PPL preferentially extracted nonpolar and terrestrially derived compounds as the target DOM. However, selfassembly may lead to more accumulation of interfering components (e.g., polar and microbial-derived compounds) than the analytes of interest. For comparison of samples, it must be considered that the choice of the elution solvent and the changing ionic strength (salinity) of the matrix can affect the DOM composition. Different mechanisms such as van der Waals forces, hydrophobic interactions, hydrogen bonding, and $\mathrm{Ca}^{2+}$ bridging regulate DOM self-assembly and might be altered by sample matrix effects. ${ }^{75}$ DOM self-assembly fundamentally changes the quality of the extracted DOM in the SPE process, resulting in (i) increased DOM molecular weight by noncovalent bonds, change in the (ii) molecular composition and (iii) optical properties, and (iv) significant reduced carbon extraction efficiency. ${ }^{60,69,76}$ By applying the online fluorometric modeling, we can optimize $\mathrm{DOC}_{\text {load }}$ and the respective sample volume by following these steps: (i) modeling PPL-based SPE processes; (ii) calculating the targeted $\mathrm{DOC}_{\text {load }}$ that yields the least chemical fractionation for the target parameter; and (iii) finally determining the optimal sample volume.

\section{ASSOCIATED CONTENT}

\section{SI Supporting Information}

The Supporting Information is available free of charge at https://pubs.acs.org/doi/10.1021/acs.est.1c04535.

Amino acid measurement method, estimates of the quality for model fitting, EEM contours of six components in the permeate, chemical changes in the permeate, EEM contours for original seawater Ms1, wavelength-dependent differences of FDOM extraction efficiency at different $\mathrm{DOC}_{\text {load }}$, cluster analysis based on relative distributions of all extracted total dissolved amino acids, additional SEM images for visible DOM on the surface of PPL sorbent, SpectraSuite-parameters for online fluorescence measurement, gradient programs for polarity profile and amino acid measurement, and amino acid distribution in the methanol extracts (PDF)

\section{AUTHOR INFORMATION}

\section{Corresponding Authors}

Xianyu Kong - Alfred Wegener Institute Helmholtz Centre for Polar and Marine Research, 27570 Bremerhaven, Germany; ๑ orcid.org/0000-0002-7366-5180; Email: Xianyu.Kong@ awi.de

Boris P. Koch - Alfred Wegener Institute Helmholtz Centre for Polar and Marine Research, 27570 Bremerhaven, Germany; University of Applied Sciences, 27568 Bremerhaven, Germany; Email: Boris.Koch@awi.de

\section{Authors}

Thomas Jendrossek - Alfred Wegener Institute Helmholtz Centre for Polar and Marine Research, 27570 Bremerhaven, Germany

Kai-Uwe Ludwichowski - Alfred Wegener Institute Helmholtz Centre for Polar and Marine Research, 27570 Bremerhaven, Germany

Ute Marx - Alfred Wegener Institute Helmholtz Centre for Polar and Marine Research, 27570 Bremerhaven, Germany

Complete contact information is available at:

https://pubs.acs.org/10.1021/acs.est.1c04535

\section{Notes}

The authors declare no competing financial interest.

\section{ACKNOWLEDGMENTS}

X.K. was funded by the China Scholarship Council (201809370078). The authors are thankful to Claudia Burau for supporting the DOC analyses.

\section{REFERENCES}

(1) Hopkinson, C. S.; Vallino, J. J. Efficient Export of Carbon to the Deep Ocean through Dissolved Organic Matter. Nature 2005, 433, 142-145.

(2) Ksionzek, K. B.; Lechtenfeld, O. J.; McCallister, S. L.; SchmittKopplin, P.; Geuer, J. K.; Geibert, W.; Koch, B. P. Dissolved Organic Sulfur in the Ocean: Biogeochemistry of a Petagram Inventory. Science 2016, 354, 456-459.

(3) Ksionzek, K. B.; Zhang, J.; Ludwichowski, K. U.; Wilhelms-Dick, D.; Trimborn, S.; Jendrossek, T.; Kattner, G.; Koch, B. P. Stoichiometry, Polarity, and Organometallics in Solid-Phase Extracted Dissolved Organic Matter of the Elbe-Weser Estuary. PLoS One 2018, 13, No. e0203260.

(4) Perminova, I. V.; Dubinenkov, I. V.; Kononikhin, A. S.; Konstantinov, A. I.; Zherebker, A. Y.; Andzhushev, M. A.; Lebedev, V. A.; Bulygina, E.; Holmes, R. M.; Kostyukevich, Y. I.; Popov, I. A.; Nikolaev, E. N. Molecular Mapping of Sorbent Selectivities with Respect to Isolation of Arctic Dissolved Organic Matter as Measured by Fourier Transform Mass Spectrometry. Environ. Sci. Technol. 2014, 48, 7461-7468.

(5) Lewis, C. B.; Walker, B. D.; Druffel, E. R. M. Isotopic and Optical Heterogeneity of Solid Phase Extracted Marine Dissolved Organic Carbon. Mar. Chem. 2020, 219, 103752.

(6) Hockaday, W. C.; Purcell, J. M.; Marshall, A. G.; Baldock, J. A.; Hatcher, P. G. Electrospray and Photoionization Mass Spectrometry for the Characterization of Organic Matter in Natural Waters: A Qualitative Assessment. Limnol Oceanogr. Methods 2009, 7, 81-95.

(7) Chen, H.; Stubbins, A.; Hatcher, P. G. A Mini-Electrodialysis System for Desalting Small Volume Saline Samples for Fourier Transform Ion Cyclotron Resonance Mass Spectrometry. Limnol Oceanogr. Methods 2011, 9, 582-592.

(8) Green, N. W.; Perdue, E. M.; Aiken, G. R.; Butler, K. D.; Chen, H.; Dittmar, T.; Niggemann, J.; Stubbins, A. An Intercomparison of Three Methods for the Large-Scale Isolation of Oceanic Dissolved Organic Matter. Mar. Chem. 2014, 161, 14-19.

(9) Mopper, K.; Stubbins, A.; Ritchie, J. D.; Bialk, H. M.; Hatcher, P. G. Advanced Instrumental Approaches for Characterization of Marine Dissolved Organic Matter: Extraction Techniques, Mass Spectrometry, and Nuclear Magnetic Resonance Spectroscopy. Chem. Rev. 2007, 107, 419-442.

(10) Dittmar, T.; Koch, B.; Hertkorn, N.; Kattner, G. A Simple and Efficient Method for the Solid-Phase Extraction of Dissolved Organic Matter (SPE-DOM) from Seawater. Limnol Oceanogr. Methods 2008, 6, 230-235.

(11) Li, Y.; Harir, M.; Uhl, J.; Kanawati, B.; Lucio, M.; Smirnov, K. S.; Koch, B. P.; Schmitt-Kopplin, P.; Hertkorn, N. How 
Representative Are Dissolved Organic Matter (DOM) Extracts? A Comprehensive Study of Sorbent Selectivity for DOM Isolation. Water Res. 2017, 116, 316-323.

(12) Tfaily, M. M.; Hodgkins, S.; Podgorski, D. C.; Chanton, J. P.; Cooper, W. T. Comparison of Dialysis and Solid-Phase Extraction for Isolation and Concentration of Dissolved Organic Matter Prior to Fourier Transform Ion Cyclotron Resonance Mass Spectrometry. Anal. Bioanal. Chem. 2012, 404, 447-457.

(13) Swenson, M. M.; Oyler, A. R.; Minor, E. C. Rapid Solid Phase Extraction of Dissolved Organic Matter. Limnol Oceanogr. Methods 2014, 12, 713-728.

(14) Rho, H.; Chon, K.; Park, J.; Cho, J. Rapid and Effective Isolation of Dissolved Organic Matter Using Solid-Phase Extraction Cartridges Packed with Amberlite XAD 8/4 Resins. Water 2019, 11, 67.

(15) Raeke, J.; Lechtenfeld, O. J.; Wagner, M.; Herzsprung, P.; Reemtsma, T. Selectivity of Solid Phase Extraction of Freshwater Dissolved Organic Matter and Its Effect on Ultrahigh Resolution Mass Spectra. Environ. Sci.: Processes Impacts 2016, 18, 918-927.

(16) Broek, T. A. B.; Walker, B. D.; Guilderson, T. P.; McCarthy, M. D. Coupled Ultrafiltration and Solid Phase Extraction Approach for the Targeted Study of Semi-Labile High Molecular Weight and Refractory Low Molecular Weight Dissolved Organic Matter. Mar. Chem. 2017, 194, 146-157.

(17) Johnson, W. M.; Kido Soule, M. C.; Kujawinski, E. B. Extraction Efficiency and Quantification of Dissolved Metabolites in Targeted Marine Metabolomics. Limnol Oceanogr. Methods 2017, 15, 417-428.

(18) Koch, B. P.; Ludwichowski, K. U.; Kattner, G.; Dittmar, T.; Witt, M. Advanced Characterization of Marine Dissolved Organic Matter by Combining Reversed-Phase Liquid Chromatography and FT-ICR-MS. Mar. Chem. 2008, 111, 233-241.

(19) Li, Y.; Harir, M.; Lucio, M.; Gonsior, M.; Koch, B. P.; SchmittKopplin, P.; Hertkorn, N. Comprehensive Structure-Selective Characterization of Dissolved Organic Matter by Reducing Molecular Complexity and Increasing Analytical Dimensions. Water Res. 2016, 106, 477-487.

(20) Chen, M.; Kim, S.; Park, J. E.; Jung, H. J.; Hur, J. Structural and Compositional Changes of Dissolved Organic Matter upon SolidPhase Extraction Tracked by Multiple Analytical Tools. Anal. Bioanal. Chem. 2016, 408, 6249-6258.

(21) Wünsch, U. J.; Geuer, J. K.; Lechtenfeld, O. J.; Koch, B. P.; Murphy, K. R.; Stedmon, C. A. Quantifying the Impact of Solid-Phase Extraction on Chromophoric Dissolved Organic Matter Composition. Mar. Chem. 2018, 207, 33-41.

(22) Li, Y.; Harir, M.; Lucio, M.; Kanawati, B.; Smirnov, K.; Flerus, R.; Koch, B. P.; Schmitt-Kopplin, P.; Hertkorn, N. Proposed Guidelines for Solid Phase Extraction of Suwannee River Dissolved Organic Matter. Anal. Chem. 2016, 88, 6680-6688.

(23) Sleighter, R. L.; Hatcher, P. G. Molecular Characterization of Dissolved Organic Matter (DOM) along a River to Ocean Transect of the Lower Chesapeake Bay by Ultrahigh Resolution Electrospray Ionization Fourier Transform Ion Cyclotron Resonance Mass Spectrometry. Mar. Chem. 2008, 110, 140-152.

(24) Cao, F.; Zhu, Y.; Kieber, D. J.; Miller, W. L. Distribution and Photo-Reactivity of Chromophoric and Fluorescent Dissolved Organic Matter in the Northeastern North Pacific Ocean. Deep-Sea Res. Part I Oceanogr. Res. Pap. 2020, 155, 103168.

(25) Nelson, N. B.; Gauglitz, J. M. Optical Signatures of Dissolved Organic Matter Transformation in the Global Ocean. Front. Mar. Sci. 2016, 2, 118.

(26) Martias, C.; Tedetti, M.; Lantoine, F.; Jamet, L.; Dupouy, C. Characterization and Sources of Colored Dissolved Organic Matter in a Coral Reef Ecosystem Subject to Ultramafic Erosion Pressure (New Caledonia, Southwest Pacific). Sci. Total Environ. 2018, 616-617, $438-452$.

(27) Zherebker, A.; Shirshin, E.; Rubekina, A.; Kharybin, O.; Kononikhin, A.; Kulikova, N. A.; Zaitsev, K. V.; Roznyatovsky, V. A.; Grishin, Y. K.; Perminova, I. V.; Nikolaev, E. N. Optical Properties of
Soil Dissolved Organic Matter Are Related to Acidic Functions of Its Components as Revealed by Fractionation, Selective Deuteromethylation, and Ultrahigh Resolution Mass Spectrometry. Environ. Sci. Technol. 2020, 54, 2667-2677.

(28) Yamashita, Y.; Hashihama, F.; Saito, H.; Fukuda, H.; Ogawa, H. Factors Controlling the Geographical Distribution of Fluorescent Dissolved Organic Matter in the Surface Waters of the Pacific Ocean. Limnol. Oceanogr. 2017, 62, 2360-2374.

(29) Hansen, A. M.; Kraus, T. E. C.; Pellerin, B. A.; Fleck, J. A.; Downing, B. D.; Bergamaschi, B. A. Optical Properties of Dissolved Organic Matter (DOM): Effects of Biological and Photolytic Degradation. Limnol. Oceanogr. 2016, 61, 1015-1032.

(30) Carr, N.; Davis, C. E.; Blackbird, S.; Daniels, L. R.; Preece, C.; Woodward, M.; Mahaffey, C. Seasonal and Spatial Variability in the Optical Characteristics of DOM in a Temperate Shelf Sea. Prog. Oceanogr. 2019, 177, 101929.

(31) Ishii, S. K. L.; Boyer, T. H. Behavior of Reoccurring PARAFAC Components in Fluorescent Dissolved Organic Matter in Natural and Engineered Systems: A Critical Review. Environ. Sci. Technol. 2012, 46, 2006-2017.

(32) Murphy, K. R.; Timko, S. A.; Gonsior, M.; Powers, L. C.; Wünsch, U. J.; Stedmon, C. A. Photochemistry Illuminates Ubiquitous Organic Matter Fluorescence Spectra. Environ. Sci. Technol. 2018, 52, 11243-11250.

(33) Schittich, A.-R.; Wünsch, U. J.; Kulkarni, H. V.; Battistel, M.; Bregnhøj, H.; Stedmon, C. A.; McKnight, U. S. Investigating Fluorescent Organic-Matter Composition as a Key Predictor for Arsenic Mobility in Groundwater Aquifers. Environ. Sci. Technol. 2018, 52, 13027-13036.

(34) Fitznar, H. P.; Lobbes, M.; Kattner, G. Determination of Enantiomeric Amino Acids with High-Performance Liquid Chromatography and Pre-Column Derivatisation with o-Phthaldialdehyde and $\mathrm{N}$-isobutyrylcysteine in Seawater and Fossil Samples (mollusks). J. Chromatogr. A 1999, 832, 123-132.

(35) Flerus, R.; Koch, B. P.; Schmitt-Kopplin, P.; Witt, M.; Kattner, G. Molecular Level Investigation of Reactions between Dissolved Organic Matter and Extraction Solvents Using FT-ICR MS. Mar. Chem. 2011, 124, 100-107.

(36) Pucher, M.; Wünsch, U.; Weigelhofer, G.; Murphy, K.; Hein, T.; Graeber, D. StaRdom: Versatile Software for Analyzing Spectroscopic Data of Dissolved Organic Matter in R. Water 2019, $11,2366$.

(37) Lawaetz, A. J.; Stedmon, C. A. Fluorescence Intensity Calibration Using the Raman Scatter Peak of Water. Appl. Spectrosc. 2009, 63, 936-940.

(38) Murphy, K. R.; Stedmon, C. A.; Graeber, D.; Bro, R. Fluorescence Spectroscopy and Multi-Way Techniques. PARAFAC. Anal. Methods 2013, 5, 6557-6566.

(39) McKnight, D. M.; Boyer, E. W.; Westerhoff, P. K.; Doran, P. T.; Kulbe, T.; Andersen, D. T. Spectrofluorometric Characterization of Dissolved Organic Matter for Indication of Precursor Organic Material and Aromaticity. Limnol. Oceanogr. 2001, 46, 38-48.

(40) Huguet, A.; Vacher, L.; Relexans, S.; Saubusse, S.; Froidefond, J. M.; Parlanti, E. Properties of Fluorescent Dissolved Organic Matter in the Gironde Estuary. Org. Geochem. 2009, 40, 706-719.

(41) Helms, J. R.; Stubbins, A.; Ritchie, J. D.; Minor, E. C.; Kieber, D. J.; Mopper, K. Absorption Spectral Slopes and Slope Ratios as Indicators of Molecular Weight, Source, and Photobleaching of Chromophoric Dissolved Organic Matter. Limnol. Oceanogr. 2008, 53, 955-969.

(42) Lechtenfeld, O. J.; Koch, B. P.; Geibert, W.; Ludwichowski, K. U.; Kattner, G. Inorganics in Organics: Quantification of Organic Phosphorus and Sulfur and Trace Element Speciation in Natural Organic Matter Using HPLC-ICPMS. Anal. Chem. 2011, 83, 89688974.

(43) El Aferni, A.; Guettari, M.; Tajouri, T. Mathematical Model of Boltzmann's Sigmoidal Equation Applicable to the Spreading of the Coronavirus (Covid-19) Waves. Environ. Sci. Pollut. Res. 2020, 28, 40400. 
(44) Murphy, K. R.; Stedmon, C. A.; Waite, T. D.; Ruiz, G. M. Distinguishing between Terrestrial and Autochthonous Organic Matter Sources in Marine Environments Using Fluorescence Spectroscopy. Mar. Chem. 2008, 108, 40-58.

(45) Stedmon, C. A.; Markager, S.; Tranvik, L.; Kronberg, L.; Slätis, T.; Martinsen, W. Photochemical Production of Ammonium and Transformation of Dissolved Organic Matter in the Baltic Sea. Mar. Chem. 2007, 104, 227-240.

(46) Madonia, A.; Caruso, G.; Piazzolla, D.; Bonamano, S.; Piermattei, V.; Zappalà, G.; Marcelli, M. Chromophoric Dissolved Organic Matter as a Tracer of Fecal Contamination for Bathing Water Quality Monitoring in the Northern Tyrrhenian Sea (Latium, Italy). J. Mar. Sci. Eng. 2020, 8, 430.

(47) Zabłocka, M.; Kowalczuk, P.; Meler, J.; Peeken, I.; DragańskaDeja, K.; Winogradow, A. Compositional Differences of Fluorescent Dissolved Organic Matter in Arctic Ocean Spring Sea Ice and Surface Waters North of Svalbard. Mar. Chem. 2020, 227, 103893.

(48) Baghoth, S. A.; Sharma, S. K.; Amy, G. L. Tracking Natural Organic Matter (NOM) in a Drinking Water Treatment Plant Using Fluorescence Excitation-Emission Matrices and PARAFAC. Water Res. 2011, 45, 797-809.

(49) Kong, X.; Sun, Y.; Su, R.; Shi, X. Real-Time Eutrophication Status Evaluation of Coastal Waters Using Support Vector Machine with Grid Search Algorithm. Mar. Pollut. Bull. 2017, 119, 307-319.

(50) Coble, P. G. Characterization of Marine and Terrestrial DOM in Seawater Using Excitation-Emission Matrix Spectroscopy. Mar. Chem. 1996, 51, 325-346.

(51) Stedmon, C. A.; Markager, S.; Bro, R. Tracing Dissolved Organic Matter in Aquatic Environments Using a New Approach to Fluorescence Spectroscopy. Mar. Chem. 2003, 82, 239-254.

(52) Kim, J.; Kim, Y.; Kang, H. W.; Kim, S. H.; Rho, T. K.; Kang, D. J. Tracing Water Mass Fractions in the Deep Western Indian Ocean Using Fluorescent Dissolved Organic Matter. Mar. Chem. 2020, 218, 103720.

(53) Lechtenfeld, O. J.; Kattner, G.; Flerus, R.; McCallister, S. L.; Schmitt-Kopplin, P.; Koch, B. P. Molecular Transformation and Degradation of Refractory Dissolved Organic Matter in the Atlantic and Southern Ocean. Geochim. Cosmochim. Acta 2014, 126, 321-337.

(54) Mahmoud, M. A. Kinetics Studies of Uranium Sorption by Powdered Corn Cob in Batch and Fixed Bed System. J. Adv. Res. 2016, 7, 79-87.

(55) Edet, U. A.; Ifelebuegu, A. O. Kinetics, Isotherms, and Thermodynamic Modeling of the Adsorption of Phosphates from Model Wastewater Using Recycled Brick Waste. Processes 2020, 8, 665 .

(56) Moritz, M.; Geszke-Moritz, M. Sulfonic Acid DerivativeModified SBA-15, PHTS and MCM-41 Mesoporous Silicas as Carriers for a New Antiplatelet Drug: Ticagrelor Adsorption and Release Studies. Materials 2020, 13, 2913.

(57) Tartaglia, A.; Locatelli, M.; Kabir, A.; Furton, K. G.; Macerola, D.; Sperandio, E.; Piccolantonio, S.; Ulusoy, H. I.; Maroni, F.; Bruni, P.; Croce, F.; Samanidou, V. F. Comparison between Exhaustive and Equilibrium Extraction Using Different SPE Sorbents and Sol-Gel Carbowax 20M Coated FPSE Media. Molecules 2019, 24, 382.

(58) Bielicka-Daszkiewicz, K.; Voelkel, A. Theoretical and Experimental Methods of Determination of the Breakthrough Volume of SPE Sorbents. Talanta 2009, 80, 614-621.

(59) Verdugo, P.; Santschi, P. H. Polymer Dynamics of DOC Networks and Gel Formation in Seawater. Deep Sea Res. Part II Top. Stud. Oceanogr. 2010, 57, 1486-1493.

(60) Chin, W.-C.; Orellana, M. V.; Verdugo, P. Spontaneous Assembly of Marine Dissolved Organic Matter into Polymer Gels. Nature 1998, 391, 568-572.

(61) Verdugo, P.; Alldredge, A. L.; Azam, F.; Kirchman, D. L.; Passow, U.; Santschi, P. H. The Oceanic Gel Phase: A Bridge in the DOM-POM Continuum. Mar. Chem. 2004, 92, 67-85.

(62) Johnson, M. S.; Couto, E. G.; Abdo, M.; Lehmann, J. Fluorescence Index as an Indicator of Dissolved Organic Carbon
Quality in Hydrologic Flowpaths of Forested Tropical Watersheds. Biogeochemistry 2011, 105, 149-157.

(63) Passow, U. Transparent Exopolymer Particles (TEP) in Aquatic Environments. Prog. Oceanogr. 2002, 55, 287-333.

(64) Kerner, M.; Hohenberg, H.; Ertl, S.; Reckermann, M.; Spitzy, A. Self-Organization of Dissolved Organic Matter to Micelle-like Micropadicles in River Water. Nature 2003, 422, 150-154.

(65) Mann, P. J.; Spencer, R. G. M.; Hernes, P. J.; Six, J.; Aiken, G. R.; Tank, S. E.; McClelland, J. W.; Butler, K. D.; Dyda, R. Y.; Holmes, R. M. Pan-Arctic Trends in Terrestrial Dissolved Organic Matter from Optical Measurements. Front. Earth Sci. 2016, 4, 25.

(66) Chen, M.; Kim, S.; Park, J. E.; Kim, H. S.; Hur, J. Effects of Dissolved Organic Matter (DOM) Sources and Nature of Solid Extraction Sorbent on Recoverable DOM Composition: Implication into Potential Lability of Different Compound Groups. Anal. Bioanal. Chem. 2016, 408, 4809-4819.

(67) Wang, W.; He, C.; Gao, Y.; Zhang, Y.; Shi, Q. Isolation and Characterization of Hydrophilic Dissolved Organic Matter in Waters by Ion Exchange Solid Phase Extraction Followed by High Resolution Mass Spectrometry. Environ. Chem. Lett. 2019, 17, 1857-1866.

(68) Xu, H.; Guan, D.; Zou, L.; Lin, H.; Guo, L. Contrasting Effects of Photochemical and Microbial Degradation on $\mathrm{Cu}(\mathrm{II})$ Binding with Fluorescent DOM from Different Origins Contrasting Effects of Photochemical and Microbial Degradation on $\mathrm{Cu}$ (II) Binding with Fl Uorescent DOM from Different Origin. Environ. Pollut. 2018, 239, 205-214.

(69) $\mathrm{Xu}, \mathrm{H} . ;$ Guo, L. Intriguing Changes in Molecular Size and Composition of Dissolved Organic Matter Induced by Microbial Degradation and Self-Assembly. Water Res. 2018, 135, 187-194.

(70) Mathew, K. A.; Van Ardelan, M.; Gonzalez, S. V.; Vadstein, O.; Vezhapparambu, V. S.; Leiknes, Ø.; Mankettikkara, R.; Olsen, Y. Temporal Dynamics of Carbon Sequestration in Coastal North Atlantic Fjord System as Seen through Dissolved Organic Matter Characterisation. Sci. Total Environ. 2021, 782, 146402.

(71) Hertkorn, N.; Harir, M.; Cawley, K. M.; Schmitt-Kopplin, P.; Jaffé, R. Molecular Characterization of Dissolved Organic Matter from Subtropical Wetlands: A Comparative Study through the Analysis of Optical Properties, NMR and FTICR/MS. Biogeosciences 2016, 13, $2257-2277$.

(72) Hertkorn, N.; Benner, R.; Frommberger, M.; Schmitt-Kopplin, P.; Witt, M.; Kaiser, K.; Kettrup, A.; Hedges, J. I. Characterization of a Major Refractory Component of Marine Dissolved Organic Matter. Geochim. Cosmochim. Acta 2006, 70, 2990-3010.

(73) Singer, G. A.; Fasching, C.; Wilhelm, L.; Niggemann, J.; Steier, P.; Dittmar, T.; Battin, T. J. Biogeochemically Diverse Organic Matter in Alpine Glaciers and Its Downstream Fate. Nat. Geosci. 2012, 5, $710-714$.

(74) Kellerman, A. M.; Dittmar, T.; Kothawala, D. N.; Tranvik, L. J. Chemodiversity of Dissolved Organic Matter in Lakes Driven by Climate and Hydrology. Nat. Commun. 2014, 5, 3804.

(75) Kruger, B. R.; Dalzell, B. J.; Minor, E. C. Effect of Organic Matter Source and Salinity on Dissolved Organic Matter Isolation via Ultrafiltration and Solid Phase Extraction. Aquat. Sci. 2011, 73, 405417.

(76) Romera-Castillo, C.; Chen, M.; Yamashita, Y.; Jaffé, R. Fluorescence Characteristics of Size-Fractionated Dissolved Organic Matter: Implications for a Molecular Assembly Based Structure? Water Res. 2014, 55, 40-51. 